\title{
Day Care Coronary Angiogram in Bangladesh- Our Experience with 100 cases
}

\author{
Abdul Momen ${ }^{1,2}$, Md. Zulfikar Ali ${ }^{1}$, Ashraf Ur Rahman ${ }^{1}$, Reaz Mahmud Huda ${ }^{1}$, ABM Nurunnabi ${ }^{1}$,Md. \\ Monsurul Haque ${ }^{1}$, Iftequar Alam ${ }^{1}$, Shudhakor Sarker ${ }^{2}$, Mohammad Ali ${ }^{2}$, Md. Abul Alam ${ }^{1}$, Lima Asrin \\ Sayami ${ }^{1}$, Sabina Hashem ${ }^{1}$, Saqif Shahriar ${ }^{1}$, Mir Jamal Uddin ${ }^{1,2}$ \\ ${ }^{1}$ National Institute of Cardiovascular Diseases, Dhaka, ${ }^{2}$ Bangladesh Specialized Hospital, Dhaka,
}

\section{Keywords: Ischaemic heart disease, Coronary angiography, Day-care, Hospital stay.}

\begin{abstract}
:
Background: In conventional coronary angiography (CAG) by transfemoral approach patients usually need to stay at least one night in hospital. CAG by transradial approach gives the opportunity for same day hospital discharge. The objective of this study was to assess the safety and feasibly of day case CAG in Bangladesh.

Methods: This is a single operator observational study where patients admitted for CAG through transradial (conventional and distal radial) approach were included. Patients were admitted at least 2 hours before the procedure. Hemostasis was done with manual compression followed by tight gauge-rolled bandage. Predischarge criteria had been set and applied to all patients. An emergency telephone number was given to the patient and they were contacted on the next day over telephone.

Results: 30 (30\%) female and $70(70 \%)$ male were included with mean age $53 \pm 9$ SD years. Patients were discharged from the hospital on an average after $3.3 \pm 1.1$ hours of the procedure. Only 4(4\%) patients contacted to the emergency number. No bleeding complication was noted and 16(16\%) patients complained about of some puncture site pain. Radial artery patency was was maintained in $96 \%$ of the patient on subsequent follow up.

Conclusion: Same day hospital discharge is a feasible and safe alternative with similar radial artery patency rate. It will reduce the hospital cost and bed occupancy rate in a busy center in Bangladesh.
\end{abstract}

(Cardiovasc. j. 2019; 11(2): 152-158)

\section{Introduction:}

Traditionally CAG was mostly done by transfemoral approach (TFA) which usually needs the patients to be admitted in the inpatient department and had to stay one night. CAG by transradial approach (TRA) gives the opportunity for same day hospital discharge and this strategy has been taken by many hospital authorities in other parts of the world. Femoral access is perceived to be easier and facilitates quick access with relatively low risk. But findings of latest studies have made radial route to be more popular option. ${ }^{1-3}$

The hand receives a dual arterial supply from the radial angular arteries, which come together to form deep and superficial palmar arches. The radial artery (RA) unlike the femoral or brachial artery is therefore not an end artery, and in the presence of a satisfactory ulnar collateral supply, its occlusion does not usually compromise the vascular supply to the hand. Furthermore, the superficial course of the distal radial artery provides for easy compression of the artery, so that patients can mobilize as soon as the arterial sheath is removed on completion of theprocedure. ${ }^{4}$ The transradial access has several advantages over the transfemoral approach. Being an easily compressible artery, any bleeding is controllable and local vascular hemorrhagic complications are virtually eliminated. $2,5,6$ Patients may ambulate immediately after the procedure and hospital length of stay is significantly reduced. ${ }^{7-9}$ Angiography via the radial approach has become more popular throughout the world as an alternative to the

Address of Correspondence: Dr. Abdul Momen, Department of Cardiology, National Institute of Cardiovascular Diseases, Dhaka, Bangladesh. Email- abdulmomen71@yahoo.com

(C) 2018 authors; licensed and published by International Society of Cardiovascular Ultrasound, Bangladesh Chapter and Bangladesh Society of Geriatric Cardiology. This is an Open Access article distributed under the terms of the CC BY NC 4.0 (https:// creativecommons.org/licenses/by-nc/4.0). 
femoral artery technique due to its slower incidence of access site complications, earlier patient ambulation, improved patient satisfaction, and lower cost. ${ }^{6,10-15}$ Use of TRA for coronary angiography and PCI may also be associated with improved measures of quality of life and reduced costs compared with TFA. ${ }^{16-23}$

Most operators prefer the right radial approach. The main reason is the working position of the operator on the right side of the patient. However, frequently the operator needs to cross over to the left radial approach or femoral approach. In terms of feasibility and outcome, left and right transradial approaches are similar. ${ }^{24} \mathrm{~A}$ new technique in the transradial approach is to access the distal RA from the anatomical snuffbox (radial fossa) on the dorsal side of the hand. The anatomical snuffbox is a hollow space on the radial side of the wrist when the thumb is extended; it is bounded by the tendon of the extensor pollicis longus posteriorly and of the tendons of the extensor pollicis brevis and abductor pollicis longus anteriorly. The RA crosses the floor that is formed by the scaphoid and the trapezium bones. ${ }^{25}$ This artery can be used as an entry site for 4, 5 and $6 \mathrm{Fr}$ sheaths and catheters. ${ }^{26}$ Another important feature of this technique is a puncture proximal from the pollicis brevis artery and distal from the branch supplying the superficial palmar arch. ${ }^{26} \mathrm{An}$ occlusion at this site maintains antegrade flow through the superficial palmar arch. This reduces the risk of retrograde thrombus formation in the proximal RA located in the forearm, a frequent finding in patients who develop a forearm RA occlusion due to puncture trauma or hemostasis trauma at the traditional RA puncture site. Flow to the thumb will still be maintained via the superficial palmar arch preventing ischemia and hand disability.

This study was designed to assess the safety and feasibly of day case CAG via conventional and distal radial access. To the best of our knowledge this is the first study report from Bangladesh.

\section{Methodology:}

Patient selection: This is an observational study where 100 patients were discharged on the same day after an uncomplicated CAG performed mostly at the Bangladesh Specialized Hospital and few at National Institute of Cardiovascular Diseases (NICVD), Dhaka from July 2017 to September 2018.Patient admitted for CAG through transradial(conventional and distal radial) approach were included in the study. Those NSTEMI patients who had noncritical or normal coronary were included as they were discharged on the same day of the procedure. Patient undergoing ad-hoc percutaneous coronary angioplasty, STEMI patient, patient with high risk CAG profile (critical left main disease, triple vessel disease), patient converted to transfemoral approach and patients who were willing to stay had been excluded.

Criteria for Selecting CAG Patients for Same Day Discharge:

1. Patient's factors:

a. Age $<70$ years.

b. Absence of uncontrolled diabetes.

c. Serum creatinine $<1.5 \mathrm{mg} / \mathrm{dl}$.

d. LVEF $>40 \%$ in the absence of CCF.

e. Absence of acute STEMI.

2. Procedural factors

a. Absence of major complications, persistent minor procedural events, or Hemodynamic shifts.

b. Uncomplicated vascular access.

c. CAG performed before $6 \mathrm{pm}$ to allow 3-4 hours of observation before discharge on the same day.

3. Post-procedural factors

a. Freedom from symptoms.

b. Absence of ECG changes.

c. Successful achievement of the set ambulatory targets, with a walking distance of 200 meter over $5 \mathrm{~min}$ in the absence of any symptoms.

Procedure: Patients were admitted at least 2 hours before the procedure and routine biochemistry and serology were done. Baseline ECG was done in all cases and echocardiography was done if no report was available within 1 month. Informed written consent was taken and proper counseling of the procedure was done by 
specialist cardiologist. CAG was performed before $6 \mathrm{pm}$ through conventional and distal radial route.

Vascular access management: Right radial approach was taken in all cases. 6 Fr radial sheaths were taken in most cases and 5 Fr Tiger catheter was the default catheter. The transradial arterial sheath was removed immediately after the procedure. Hemostasis was done with manual compression followed by tight gauge- rolled bandage and the tightness was loosened after 2 hours. Patients were instructed to remove the bandage on the next day.

Post-procedure care: All patients were kept in close observation in the post-procedure care unit by staff that is well trained to manage any complications under the supervision of specialist cardiologist. A 12-lead electrocardiogram was done following CAG and before discharge.

Ambulation: There was no ambulatory restriction after the hemostasis had been completed. Patients were ambulated for $5 \mathrm{~min}$, with a walking distance of $200 \mathrm{~m}$ before discharge. Any patient who failed to accomplish the set ambulatory targets was considered unsuitable for same-day discharge. Vital sign check, vascular access site, and distal vascular bed examination were done immediately after ambulation for a comprehensive analysis before discharge.

Pre-discharge evaluation: Suitability for discharge required freedom from symptoms, absence of ECG changes, absence of puncture site abnormalities and successful ambulation. Before discharge patients were instructed on how to achieve hemostasis by local pressure for puncture-related bleeding. An emergency telephone number was given to the patients so that they can contact $24 / 7$ if any emergency arose.

Follow-up: All patients received a follow-up phone call from a specialist Cardiologist on the next day to address any cardiac complaints along with entry site-related problems and medication compliance. Thereafter, patients were instructed for a follow up visit with the performing cardiologist at 1 to 4 weeks.

\section{Results:}

During the study period from July 2017 to September 2018, a total of 298 cases underwent coronary procedure of which 48 were direct PCI. Of the 250CAG cases, 102 patients fulfilled the criteria for the same-day discharge, 78 patients underwent adhoc PCI, and 45 patients had high risk CAG profile, 8 patients converted to femoral route and 17 patients wished to stay.

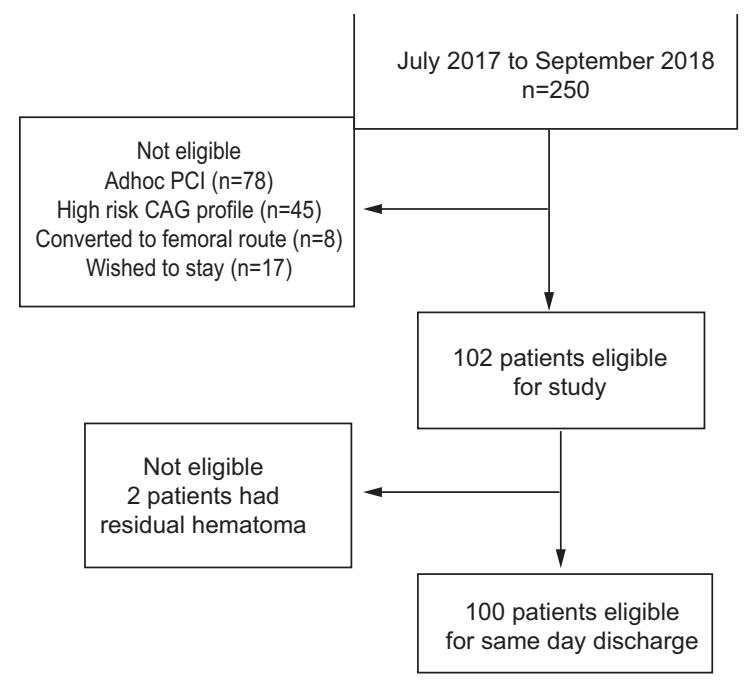

Fig.-1: Flow chart showing enrollment of patients.

102 patients were planned for same-day discharge. But 2 patients could not go home due to small residual hematoma. So; a total of 100 patients fulfilled the criteria for discharge on the same day.

\section{Table-I}

Baseline Characteristics of the study population $(n=100)$.

\begin{tabular}{lc}
\hline Baseline Characteristics & \\
Age mean (yrs) & $53.2 \pm 9 \mathrm{SD}$ \\
Sex & \\
$\quad$ Male & $70 \%$ \\
$\quad$ Female & $30 \%$ \\
Smoking & $40 \%$ \\
Hypertension & $54 \%$ \\
Diabetes & $62 \%$ \\
\hline
\end{tabular}

Table I presents the baseline characteristic. 30 (30\%) females and $70(70 \%)$ males were included with mean age 53.2 $\pm 9 \mathrm{SD}$ years. Of these 100 patients $40 \%$ was smoker, $62 \%$ had diabetes mellitus and $54 \%$ had systemic hypertension. 
Figure 2 shows the diagnosis at presentation of the study population. Unstable angina (36\%) was the most frequent diagnosis followed by chronic stable angina (30\%), old myocardial infarction (27\%) and non STEMI (7\%).



Fig.-2: Diagnosis of the patients $(n=100)$.

Table II showing that all patients were taking aspirin and statin and long acting nitrate (88\%) was the most common anti anginal drug followed by beta blocker (75\%) and calcium channel blocker (20\%).

Table-II

Medications taken by the patients $(n=100)$.

\begin{tabular}{lc}
\hline Medications at presentation & N (\%) \\
\hline Aspirin & $100(100 \%)$ \\
Clopidogrel & $73(73 \%)$ \\
Other antiplatelet & $3(3 \%)$ \\
Statin & $100 \%$ \\
Beta blocker & $75(75 \%)$ \\
ACEI/ ARB & $57(57 \%)$ \\
Nitrates & $88(88 \%)$ \\
CCB & $20(20 \%)$ \\
Other anti ischaemic drugs & $5(5 \%)$ \\
\hline
\end{tabular}

Procedural characteristics are elaborated in Table III. Right radial approach was taken in all cases. 6 Fr radial sheaths were taken in $85 \%$ cases and 5 Fr Radial catheter was used for CAG. Conventional radial approach was taken in $70 \%$ cases and the rest was distal radial approach. Tiger catheter was the default catheter and was sufficient in $95 \%$ of the cases and in the rest left or right Judkin's, right or left Amplatz catheter was taken. Mean procedure time and fluoro time were $10.2 \pm 6.3 \mathrm{SD} \mathrm{min}$ and $4.2 \pm 1.5 \mathrm{SD} \mathrm{min}$ respectively. Coronary angiographic profile is given in table IV. Normal coronary, non-critical coronary artery disease, single vessel disease and double vessel disease were found in 10(10\%),
$15(15 \%), 45(45 \%)$ and $20(20 \%)$ of patients respectively.

Table-III

Procedural characteristics.

\begin{tabular}{lc}
\hline Parameter & \\
Approach & \\
Conventional Radial & $30(70 \%)$ \\
Distal radial & \\
Radial sheath diameter & $15(15 \%)$ \\
$5 \mathrm{Fr}$ & $85(85 \%)$ \\
$6 \mathrm{Fr}$ & \\
Catheter used & $95(95 \%)$ \\
$\quad$ Tiger catheter (5Fr) & $5(5 \%)$ \\
$\quad$ Others & $12 \pm 4.5 \mathrm{SD}$ \\
Procedural time (min) & $4 \pm 3.1 \mathrm{SD}$ \\
Fluoroscopy time (min) &
\end{tabular}

Table-IV

Coronary angiographic profile of the study patients.

Character

SVD

$45(35 \%)$

DVD

$30(30 \%)$

Noncritical lesion

$15(15 \%)$

Normal coronaries

$10(10 \%)$

Follow up: There was no incidence of any major complications during the 3 to 4 hour triage period. 8 patients developed minor hematoma, which was timely diagnosed and effectively reduced by manual compression. But 2 patients had residual hematoma after 4 hours; so they were excluded from the study. There was no haemodynamic instability or any ECG changes. All patients were discharged from the hospital after a mean $3.3 \pm 1.1$ hours of the procedure. Only 4(4\%) patients contacted to the emergency number. All patients were called on the next day to address any cardiac complaints along with entry site-related problems.

Table-V

Follow up of the patients on the next day.

\begin{tabular}{lc}
\hline Repeat chest pain & $0 \%$ \\
Bleeding & $0 \%$ \\
Puncture site pain & $16 \%$ \\
Medication compliance & $100 \%$ \\
\hline
\end{tabular}


No bleeding complication was noted and 16(16\%) patients complained about of some puncture site pain and none of the patient complained about unstable angina (Table V). Radial artery patency was checked by palpatory method and was maintained in $96 \%$ of the patients on subsequent follow up after 2 to 3 weeks.

Another important finding is that our conversion rate to femoral route is $3 \%$ ( 8 out of 250 cases) which indicates that radial approach is feasible in almost all cases of coronary intervention.

\section{Discussion:}

The present study demonstrates that same-day discharge after coronary angiogram in radial route can be performed safely in patients with stable cardiac status in the context of Bangladesh. Day care CAG did not lead to unattended cardiac events or any increase in post procedural complications. Furthermore, it was found that after an uncomplicated procedure, a 3-4 hours observation period allowed adequate triage of patients to same-day discharge. This is the first study of same-day discharge after elective CAG in Bangladesh.

Our protocol had only a few exclusion criteria, and one was angiographic. The patients included in our study represent a general elective CAG population through radial or distal radial route. Our study reflects that patients at risk for post procedural complications can be identified effectively in a day-case setting on the basis of predefined clinical and angiographic criteria. The present study shows that triage of 3-4 hours after CAG through radial route is good enough for the safety of a same-day discharge protocol. After CAG, only 2 patients developed an indication for extended hospital stay during the 4 hours observation period due to residual hematoma.

Post CAG length of stay was a mean of $3.3 \pm 1.1$ hours. Before discharge; all patients were asymptomatic and could accomplish the set ambulatory targets. There was no haemodynamic instability or any ECG changes. While follow up on the next day over telephone, only $16 \%$ patients reported some minor puncture site pain. The absence of adverse cardiac events may be explained by the exclusion of STEMI patients. Also in case of NSTEMI and unstable angina patients; CAG was done in the index hospitalization after initial stabilization of the patients which justifies the appropriateness of the selection criteria implemented in this study. They were discharged on the same day of procedure either due to normal or non critical coronary artery disease.

Studies related to same day discharge are mostly done on carefully selected elective PCI patients. There are 7 randomized controlled trials (RCTs) $(\mathrm{n}=2,738)$ and 30 observational studies $(\mathrm{n}=$ 10,065) which assessed the safety of same-day discharge in patients undergoing PCI. The vascular access site was predominantly transradial in the randomized cohort (60.8\%) and transfemoral in the observational cohort (70.0\%). A meta-analysis of these studies revealed that in selected patients undergoing largely elective PCI, same-day discharge was associated with a low rate of major complications and appeared to be as safe as routine overnight observation. ${ }^{27}$ Though our study is based on elective CAG patients only; findings of this study may stimulate protocol for same day discharge of selected PCI patients in the context of Bangladesh.

With improvements in the surgical techniques and safety over the past several years, there is increased trend of performing varieties of noncardiac surgeries in the outpatient setting. Over $65 \%$ of surgeries performed in North America are done in the outpatient setting. On the other side, though interventional technologies improved significantly in recent years, there has been only marginal reduction in the post coronary intervention length of stay. The length of stay following CAG and PCI is one of the major determinants of hospital cost and quality of-care assessment. EASY (Early Discharge after Transradial Stenting of Coronary Arteries) trial showed that same-day home discharge after uncomplicated transradial PCI resulted in a $50 \%$ relative reduction in medical costs. There are extreme variations in the length of stay between countries, regions, and hospitals. But length of stay shows a decreasing trend over time and shorter length of stay does not appear to affect health outcomes adversely as demonstrated in various other day care procedures. ${ }^{28-35}$ 
The first study on same-day discharge reported by Kiemeneijet al. ${ }^{34}$ clearly demonstrated safety of early ambulation after transradial PCI. Slagboom et al. ${ }^{35}$ later reported safety of transradial PCI with 6 -F guiding catheters and $40 \%$ usage of stents in the OUTCLAS (Outpatient Coronary Low-Profile Angioplasty Study) trial. Ziakaset al. ${ }^{36}$ have shown that same-day discharge after radial coronary intervention in certain low-risk patients is a safe and feasible strategy because it enables immediate ambulation. Largest study of same day discharge which included 2400 patients done by Mehul Patel et al. has shown that when appropriately selected, with strict adherence to the set protocol, sameday discharge after uncomplicated elective PCI is safe despite using femoral access in a wide spectrum of patients. ${ }^{37,38}$

All the above studies were done mostly in PCI patients and in Western and developed countries. In a south Asian country like Bangladesh lack of proper infrastructure and patient education system, social diversity and poor transportation system are all impediments to day care procedures. But at the same time shortage of specialized hospitals with higher patient to bed ratio and skilled man power may all would make the day care procedures significantly cost effective in high volume hospitals with coronary intervention facilities. Our study showed the safety and feasibility of day care CAG in the Bangladeshi perspective.

\section{Conclusion:}

Same day hospital discharge is a feasible and safe alternative with similar radial artery patency rate. It will reduce the hospital cost and bed occupancy rate in a busy center in Bangladesh. Our study demonstrates that day based coronary angiogram can be done without compromising the qualityof-care or safety in the properly selected patient population. Shorter length of stay with same day discharge may contribute to reduce burden on healthcare resources and also promote improved patient satisfaction.

\section{Conflict of Interest - None.}

\section{References:}

1. Romagnoli E, Biondi-Zoccai G, Sciahbasi A, Politi L, Rigattieri S, Pendenza G, et al. Radial versus femoral randomized investigation in ST-segment elevation acute coronary syndrome: the RIFLE-STEACS (Radial Versus Femoral Randomized Investigation in ST-Elevation Acute Coronary Syndrome) study. J Am Coll Cardiol 2012 Dec 18;60(24):2481-2489.

2. Cooper CJ, El-Shiekh RA, Cohen DJ, Blaesing L, Burket MW, Basu A, et al. Effect of transradial access on quality of life and cost of cardiac catheterization: a randomized comparison. Am Heart J 1999 (Sep 1);138(3):430-436.

3. Jolly SS, Yusuf S, Cairns J, Niemelä K, Xavier D, Widimsky $P$, et al. Radial versus femoral access for coronary angiography and intervention in patients with acute coronary syndromes (RIVAL): a randomised, parallel group, multicentre trial. Lancet 2011 (Apr 23);377(9775):1409-1420.

4. Archbold RA, Robinson NM, Schilling RJ. Radial artery access for coronary angiography and percutaneous coronary intervention. BMJ 2004 (Aug 21);329(7463):443.

5. Kiemeneij F, Laarman GJ, Odekerken D, Slagboom T, van der Wieken R. A randomized comparison of percutaneous transluminal coronary angioplasty by the radial, brachial and femoral approaches: the access study. J Am Coll Cardiol 1997 (May 1);29(6):1269-1275.

6. Cubeddu MG, Schneider JE, Arrowood M. Right radial access for PTCA: a prospective study demonstrates reduced complications and hospital charges. J Invasive Cardiol 1996; 8: 40D-4D.

7. Valsecchi O, Musumeci G, Vassileva A, Tespili M, Guagliumi G, Gavazzi A, Ferrazzi P. Safety, feasibility and efficacy of transradial primary angioplasty in patients with acute myocardial infarction. Ital Heart J 2003 (May); 4(5): 329-334.

8. Achenbach S, Ropers D, Kallert L, Turan N, Krähner R, Wolf T, et al. Transradial versus transfemoral approach for coronary angiography and intervention in patients above 75 years of age. Catheter Cardiovasc Interv 2008 Nov 1; 72(5): 629-635.

9. Hildick Smith DJ, Walsh JT, Lowe MD, Petch MC. Coronary angiography in the fully anticoagulated patient: the transradial route is successful and safe. Catheter Cardiovasc Interv2003 Jan; 58(1): 8-10.

10. Kiemeneij F, Laarman GJ, de Melker E. Transradial artery coronary angioplasty. Am Heart J1995 Jan 1; 129(1): 1-7.

11. Lotan C, Hasin Y, Mosseri M, Rozenman Y, Admon D, Nassar H, et al. Transradial approach for coronary angiography and angioplasty. Am J Cardiol 1995 Jul 15; 76(3): 164-167.

12. Hildick-Smith DJ, Ludman PF, Lowe MD, Stephens NG, Harcombe AA, Walsh JT, et al. Comparison of radial versus brachial approaches for diagnostic coronary angiography when the femoral approach is contraindicated. Am J Cardiol 1998 Mar; 81(6): 770-772.

13. Saito S. Transradial approach. Catheter Cardiovasc Interv 2001; 53: 269-270.

14. Hamon M, Sabatier R, Zhao Q, Niculescu R, Valette B, Grollier G. Mini invasive strategy in acute coronary 
syndromes: Direct coronary stenting using 5 Fr guiding catheters and transradial approach. Catheter Cardiovasc Interv2002 Mar; 55(3): 340-343.

15. Stella PR, Kiemeneij F, Laarman GJ, Odekerken D, Slagboom T, Van der Wieken R. Incidence and outcome of radial artery occlusion following transradial artery coronary angioplasty. Catheter Cardiovasc Diagn 1997 Feb 1; 40(2): 156-158.

16. Jolly SS, Yusuf S, Cairns J, Niemelä K, Xavier D, Widimsky $\mathrm{P}$, et al. Radial versus femoral access for coronary angiography and intervention in patients with acute coronary syndromes (RIVAL): a randomised, parallel group, multicentre trial. Lancet 2011 (Apr 23); 377(9775): 14091420.

17. Valgimigli M, Gagnor A, Calabró P, Frigoli E, Leonardi S, Zaro T, et al. Radial versus femoral access in patients with acute coronary syndromes undergoing invasive management: a randomized multicentre trial. Lancet 2015 (Jun 20); 385(9986): 2465-2476.

18. Cooper CJ, El-Shiekh RA, Cohen DJ, Blaesing L, Burket MW, Basu A, et al. Effect of transradial access on quality of life and cost of cardiac catheterization: a randomized comparison. Am Heart J 1999 (Sep 1); 138(3): 430-436.

19. Hess CN, Krucoff MW, Sheng S, Anstrom KJ, Barham WB, Gilchrist IC, et al. Comparison of quality-of-life measures after radial versus femoral artery access for cardiac catheterization in women: Results of the Study of Access Site for Enhancement of Percutaneous Coronary Intervention for Women quality-of-life substudy. Am Heart $J 2015$ (Aug 1); 170(2): 371-379.

20. Mitchell MD, Hong JA, Lee BY, Umscheid CA, Bartsch SM, Don CW. Systematic review and cost-benefit analysis of radial artery access for coronary angiography and intervention. Circ Cardiovasc Qual Outcomes 2012 Jan 1: CIRCOUTCOMES-112.

21. Safley DM, Amin AP, House JA, Baklanov D, Mills R, Giersiefen H, Bremer A, Marso SP. Comparison of costs between transradial and transfemoral percutaneous coronary intervention: a cohort analysis from the Premier research database. Am Heart J 2013 (Mar 1); 165(3): 303309.

22. Amin AP, House JA, Safley DM, Chhatriwalla AK, Giersiefen H, Bremer A, et al. Costs of transradial percutaneous coronary intervention. JACC: Cardiovasc Interv 2013 (Aug 1); 6(8): 827-834.

23. Amin AP, Patterson M, House JA, Giersiefen H, Spertus JA, Baklanov DV, et al. Costs associated with access site and same-day discharge among Medicare beneficiaries undergoing percutaneous coronary intervention: an evaluation of the current percutaneous coronary intervention care pathways in the United States. JACC: Cardiovasc Interv2017; 10(4): 342-351.

24. Shah RM, Patel D, Abbate A, Cowley MJ, Jovin IS. Comparison of transradial coronary procedures via right radial versus left radial artery approach: A meta analysis. Catheter Cardiovasc Interv 2016 (Dec); 88(7):1027-1033.

25. Cerda A, del Sol M. Anatomical Snuffbox and it Clinical Significance. A Literature Review. Int J Morphol 2015 Dec 1; 33(4): 1350-1360.
26. Kiemeneij F. Left distal transradial access in the anatomical snuffbox for coronary angiography (ldTRA) and interventions (ldTRI). EuroIntervention 2017 Sep; 13(7): 851-857.

27. Brayton KM, Patel VG, Stave C, de Lemos JA, Kumbhani DJ. Same-day discharge after percutaneous coronary intervention: a meta-analysis. J Am Coll Cardiol 2013 (Jul 23); 62(4): 275-285.

28. Wu C, Hannan EL, Walford G, Ambrose JA, Holmes DR, King SB, et al. A risk score to predict in-hospital mortality for percutaneous coronary interventions. J Am Coll Cardiol 2006 (Feb 7); 47(3): 654-660.

29. Chowdhary S, Ivanov J, Mackie K, Seidelin PH, D • avík V. The Toronto score for in-hospital mortality after percutaneous coronary interventions. Am Heart J 2009 (Jan 1); 157(1): 156-163.

30. Singh M, Rihal CS, Lennon RJ, Spertus J, Rumsfeld JS, Holmes Jr DR. Bedside estimation of risk from percutaneous coronary intervention: the new Mayo Clinic risk scores. Mayo Clin Proc 2007 Jun 1; 82(6): 701-708.

31. Ellis SG, Vandormael MG, Cowley MJ, DiSciascio G, Deligonul U, Topol EJ, et al. Coronary morphologic and clinical determinants of procedural outcome with angioplasty for multivessel coronary disease. Implications for patient selection. Multivessel Angioplasty Prognosis Study Group. Circulation 1990 (Oct 1); 82(4): 1193-1202.

32. Koch KT, Piek JJ, de Winter RJ, David GK, Mulder K, Tijssen JG, et al. Safety of low dose heparin in elective coronary angioplasty. Heart 1997 Jun 1; 77(6): 517-522.

33. Reiley P, Iezzoni LI, Phillips R, Davis RB, Tuchin L, Calkins D. Discharge planning: comparison of patients' and nurses' perceptions of patients following hospital discharge. Image J Nurs Sch 1996 (Jun 1); 28(2): 143-147.

34. Kiemeneij F, Laarman GJ, Slagboom T, van der Wieken R. Outpatient coronary stent implantation. J Am Coll Cardiol1997 (Feb 1); 29(2): 323-327.

35. Slagboom T, Kiemeneij F, Laarman GJ, van der Wieken R, Odekerken D. Actual outpatient PTCA: results of the OUTCLAS pilot study. Catheter Cardiovasc Interv 2001 (Jun);53(2):204-208.

36. Ziakas AA, Klinke BP, Mildenberger CR, Fretz DE, Williams EM, Kinloch FR, et al. Safety of same-daydischarge radial percutaneous coronary intervention: a retrospective study. Am Heart J 2003 (Oct 1); 146(4): 699704.

37. Bertrand OF, Rodés-Cabau J, Larose E, Rinfret S, Gaudreault V, Proulx G, et al. Early Discharge after Transradial Stenting of CoronarY Arteries in Acute Myocardial Infarction (EASY-MI) Study Investigators. Intracoronary compared to intravenous abciximab and highdose bolus compared to standard dose in patients with STsegment elevation myocardial infarction undergoing transradial primary percutaneous coronary intervention: a two-by-two factorial placebo-controlled randomized study. Am J Cardiol 2010; 105: 1520-1527.

38. Patel M, Kim M, Karajgikar R, Kodali V, Kaplish D, Lee $\mathrm{P}$, et al. Outcomes of patients discharged the same day following percutaneous coronary intervention. JACC Cardiovasc Interv 2010 (Aug 1); 3(8): 851-858. 